\title{
LA FUNDAMENTACIÓN DE LA ÉTICA ARISTOTÉLICA
}

ALFONSO GÓMEZ-LOBO

GEORGETOWN UNIVERSITY

En algunas discusiones de ética se suele invocar algo así como un punto de partida, situado por lo general fuera de la érica misma, que permitiría justificar un sistema normativo. A esto se le suele llamar "los fundamentos" o "el fundamento" de una ética dada. ${ }^{1}$

No siempre se establece claramente en qué consiste o qué aporta una estrategia de este tipo. A veces se trata sólo de establecer una cierta consistencia lógica, como cuando se dice que el fundamento del emotivismo es la clasificación neopositivista de todas las proposiciones genuinas en proposiciones empíricas y proposiciones analíticas. Si esto es verdad, entonces se sigue que no puede haber genuinas afirmaciones valorativas o normativas, pues éstas no caen bajo ninguna de las dos categorías previamente aceptadas. Dichas aserciones, por lo tanto, sólo pueden ser expresiones emotivas de aprobación o rechazo por parte de quien las enuncia. ${ }^{2}$

A veces, en cambio, se espera algo más que el despliegue de la consistencia de una metaćtica. Se espera que quien acepte los fundamentos se vea forzado a aceptar también ciertas normas que se seguirían de ellos. Una ética fundada sobre la dignidad de la persona humana, se podría sugerir, obliga a aceptar la norma de que no se debe tratar jamás a un individuo humano como un mero instrumento. En este caso tendríamos que la proposición normativa $Q$ depende de una proposición previa $P$ que la justifica. La justificación será legítima, por cierto, sólo si la inferencia de $Q$ a partir de $P$ es una inferencia lógicamente válida.

En este punto surge una importante dificultad. Si la primera proposición, la que hace de fundamento, está fuera de la ética y es, por lo tanto, descriptiva de un estado de cosas y si, en cambio, la segunda es normativa, la inferencia no será jamás válida. Esto es así en virtud del carácter analítico de toda inferencia válida. Si algo no está en las premisas, en este caso la fuerza normativa, no

1 Este trabajo corresponde al texto de una conferencia dictada en la Universidad Nacional Autónoma de México en noviembre de 1989. Me he permitido incluir algunas ideas que he desarrollado en "The ergon inference", Pbronesis, no. 34, 1989, pp. 170-184.

${ }^{2}$ Cfr. A.J. Ayer, Language, Truth and Logic, Nueva York, 1952, pp. 31-32, 102-108. 
podrá estarlo tampoco en la conclusión. Pretender que una inferencia de este tipo sea válida es cometer la falacia naturalista, es pretender inferir valores o normas a partir de hechos. ${ }^{3}$

Existe, empero, una ética cuyos admiradores tienden a presentar como sólidamente basada en un fundamento metafísico, sobre una recta consideración de la naturaleza humana. Me refiero, por cierto, a la ética aristotélica. Según esta interpretación, Aristóteles habría tomado como punto de partida algunas nociones de su Metafisica (tales como la noción de potencia y la de actualización) y de su De Anima (por ejemplo, la caracterización del ser humano como un ser dotado de una potencia o capacidad racional) para inferir de allí la idea matriz de su filosofía moral, la idea de que el bien humano consiste en la actualización de la capacidad racional característica de nuestra especie.

Cuando se objeta que quizás ese proceso de fundamentación implica cometer la falacia naturalista, se suelen proponer dos tipos de respuesta. Por una parte hay quienes sostienen que es perfectamente lícito derivar el deber ser a partir del ser. A veces se aduce, por ejemplo, que si un individuo es médico se sigue sin vicio lógico que debe prestarle ayuda a un herido que encuentre en su camino.' Por otra parte, hay quienes insisten (correctamente, a mi juicio) en que la noción aristotélica de naturaleza humana no es descriptiva sino normativa. No nos dice cómo son los seres humanos, sino cómo deberían ser.

A la primera línea de defensa yo respondería que ningún ejemplo de inferencia lícita del deber ser a partir del ser descansa sobre una premisa puramente descriptiva. Si así fuese, sería inválida, como vimos, en virtud de la analiticidad de la conexión entre las premisas y la conclusión. Lo que le confiere plausibilidad al ejemplo de inferencia de una obligación a partir del hecho de ser médico es que la noción de médico tiene fuertes componentes normativos, tradicionalmente asociados con el juramento hipocrático. No me internaré, empero, por esta vía de discusión. ${ }^{4}$

A la segunda línea de defensa habría que responder preguntando por el modo como obtenemos esa noción normativa de naturaleza humana. Si ésta

3 Sobre la reducción de la validez a analiticidad cfr. R.M. Hare, The Language of Moralr, Oxford, 1952, p. 32. No quiero sugerir, empero, que la idea subyacente sea una gran novedad: se trata de una tesis explícitamente aceptada por la escolástica tradicional. Cfr. Ioannis a Sancto Thoma, O.P., Ars Logica seu De Forma et Materia Raciocinandi, nova editio a B. Reiser exarata, Taurini, 1930, p. 75 (antecedens debet continere in se veritatem consequentis) y Carolus Frick, S.J., Introductio in Philosophiam, Logica (Philosophia Lacensis), Friburgi Brisgoviae, 1914, p. 142 (Premissae recti ratiocinii implicite virtualiter continent conclusionem). La preocupación por evitar la falacia naturalista que se constata en gran parte de la filosofía moral del siglo XX se debe sin duda a la influencia de los Principia Ethica de G.E. Moore, Cambridge, 1903, aunque la formulación de la falacia misma en este libro es extremadamente defectuosa.

4 Para estudiar un tratamiento de este tema desde la posición contraria a la ofrecida aquí véase A. Mac Intyre, After Virtue, Notre Dame, 1981, pp. 54-57. 
fuese descriptiva podríamos aducir evidencia empírica o constancias estadísticas. Pero, ¿cómo se justifica una noción normativa de esta índole? ¿Por qué sería propio de la naturaleza humana el poseer un atributo conectado analíticamente con el deber de abstenerse de matar a otros seres humanos arbitrariamente? ¿Por qué no posee un atributo conectado con la licitud de la actividad contraria? ¿Por qué ha de estar más cerca de nuestra naturaleza la moderación o sofrosyne que el desenfreno o libre satisfacción de los propios deseos?

A mi juicio, es posible responder a estas preguntas en forma satisfactoria, pero ciertamente no por la vía de hacer de la naturaleza humana el fundamento de la ética. Por el contrario, habría que desarrollar otro fundamento de modo que la formulación de lo que constituye la naturaleza humana sea una noción fundada y no fundante.

Lo que me propongo argumentar aquí es que esta idea fluye rigurosamente de la ética de Aristóteles. Trataré de mostrar que en esta filosofía moral no se invoca en ningún momento un fundamento exterior a la érica, vale decir que el sistema normativo no está fundado sobre consideraciones metafísicas, ni tampoco descansa sobre una antropología filosófica (o psicología racional, como se decía antes). Dicho sistema es, por cierto, lógicamente consistente con importantes tesis de metafísica aristotélica y en varios puntos del desarrollo de la ética se aducen doctrinas del De Anima, pero esto no significa que dichas tesis o doctrinas funcionen como fundamentos, es decir, como premisas primeras.

La mera formulación del proyecto hace pensar que está destinado al fracaso. Todo lector de la Ética Nicomaquea sabe que la concepción aristotélica de la ética es eudemonística, que parte de la definición de eudaimonia o felicidad, y que esta definición es inferida a partir de una determinada concepción del ergon (obra, tarea, función, actividad específica, típica o característica) del ser humano.

Así, por ejemplo, W. F. R. Hardie en su influyente libro sobre la teoría ética de Aristóteles sostiene que

partiendo de la concepción de las potencias específicas o peculiares de los seres humanos en cuanto miembros de la clase de los seres vivos, Aristóteles llega a una definición tentativa del bien humano (1097 a 33-1098 a 20). ${ }^{5}$

Otros autores contemporáneos ponen aún más énfasis en la idea de que nuestro conocimiento del bien humano, es decir, de aquel estado en que un ser

5 W. F. R. Hardie, Aristotle's Ethical Theory, 2a ed., trad. A. Gómez-Lobo, Oxford, 1980, p. 362. Lo mismo vale para toda otra traducción, salvo que se indique lo contrario. 
humano es bueno o de buena calidad depende de la captación de su actividad específica. K. Wilkes, p. ej., ha sostenido que

Un estudio del ergon del hombre, por consiguiente, puede decirnos en qué consiste ser un buen ser humano, una vez que hayamos descubierto cuáles actividades son efectivamente las rípicamente humanas. ${ }^{6}$

Aparentemente, lo sugerido aquí es que la actividad teorética de descubrir lo específico de una clase natural, en este caso la clase de los seres humanos, tendría la implicación práctica de permitir la valoración de individuos pertenecientes a dicha clase.

Me parece que esa consecuencia la extrae específicamente T. Nagel al afirmar que:

El ergon propio del hombre, aquello por lo cual se mide la excelencia humana, es aquello que lo hace un hombre más bien que cualquier otra cosa. [El subrayado es mío, no de Nagel].?

Esta cita sugiere que la actividad característicamente humana provee algo así como una vara que nos permite medir la buena calidad o excelencia humana. Según esto (y si se me permite usar los términos griegos para acentuar la paradoja), el ergon sería el metron de la arete.

Lo que parece emerger de estos ejemplos tomados más o menos al azar de la investigación actual sobre Aristóteles es un esquema de interpretación del proceso de fundamentación de la ética aristotélica que podríamos presentar en forma más precisa de la siguiente manera:

(Premisa 1) “Los seres humanos tienen la actividad característica $E^{\text {”. }}$

(Conclusión) "El bien para los seres humanos es el ejercicio de la actividad característica $E^{\prime \prime}$.

Obviamente esta inferencia no es válida, por eso es razonable suponer que quienes sostienen este tipo de interpretación quizás confían tácitamente en un premisa adicional, universal y valorativa, que le daría validez:

"El bien para cualquier ente (o al menos para toda sustancia natural viva) es el ejercicio de su actividad característica o ergon."

En palabras más simples, se supondría que es bueno para los seres vivos el actualizar sus potencias vitales: para el ave es bueno volar, para el pez, nadar,

6 K. V. Wilkes, "The good man and the good for man in Aristotle's ethics", en A. O. Rorty (comp.), Essays in Aristotle's Ethics, Berkeley, 1980, p. 362.

7 T. Nagel, "Aristotle on eudaimonia”, en Rorty (comp.), op. cit., p. 8. 
para la alondra, cantar. ${ }^{8}$ El bien para los seres humanos no sería más que una aplicación particular de esta simple y hermosa ley universal. ${ }^{9}$

En las páginas que siguen me propongo destruir el hechizo de esta visión y mostrar que esta manera de entender la fundamentación de la ética aristotélica es errónea. Aristóteles, sostendré, no infiere el bien humano a partir del ergon humano, ni menos aún concibe el ergon como la medida o metron de la excelencia o arete.

Una posición aparentemente tan heterodoxa como la enunciada resultará persuasiva sólo si se apoya sobre una rigurosa interpretación textual. Analizaré por lo tanto un pasaje clave, el pasaje en que Aristóteles de hecho infiere la definición de la felicidad. Se trata de una larga oración condicional que aparece en el capítulo séptimo del Libro I de la Ética Nicomaquea. Antes de proceder a analizarla conviene decir algunas palabras acerca del contexto en que aparece.

En la E.N. Aristóteles sugiere inicialmente que si lo típico de los actos humanos es perseguir un fin, es decir, un bien, y si no siempre elegimos un fin en vista de algo ulterior, vale decir, si la subordinación de fines no se prolonga al infinito, entonces ese fin último donde se detienen nuestros anhelos será el bien humano, lo mejor para nosotros. ${ }^{10}$ Existe un alto grado de unanimidad en cuanto al nombre de ese fin último. En griego se le llama eudaimonia o felicidad, florecer, prosperar, medrar. ${ }^{11}$

Las dificultades surgen cuando se trata de decir en qué consiste. Aquí se acaba la unanimidad y aparece una gran diversidad de opiniones. Luego de mencionar algunas de ellas, Aristóteles procede a desarrollar su propia posición.

Primero establece dos condiciones que debe satisfacer una respuesta correcta a la pregunta "iqué es la felicidad?" y luego define una estrategia que garantice que se llegará a la respuesta verdadera.

Las dos condiciones son (1) que la definición de eudaimonia debe especificar algo que sea final, es decir, algo que nunca sea elegido en razón de algo ulterior, y (2) algo que sea suficiente por sí sólo o autárquico, vale decir, algo que incluya dentro de sí todos los bienes y que, por ende, no necesite ser

8 Cfr. J. Barnes, Aristotle, Oxford, 1982, p. 56 (it is good for ducks to swim).

${ }^{9}$ Cfr. Aristotie, Selected Works, trad. H. Apostle y L. Gerson, Grinell, 1983, p. 415 (en el índice de la Ética Nicomaquea provisto por los traductores: Man's good is man's function).

${ }^{10}$ E.N. I 2 1093b 18-22. A lo largo de todo este trabajo he utilizado la edición crítica de I. Bywater (Aristotelis, Ethica Nicomachea, Oxford Classical Texts, Oxford, reimp. 1957). Las traducciones son mías, salvo que se indique expresamente lo contrario.

11 E.N. I 4 1095a 17-20. 
completado desde fuera. ${ }^{12}$ Todo esto requiere de mayor esclarecimiento, pero no puedo detenerme aquí para proveerlo.

La estrategia consiste en partir del ergon del ser humano, un modo de proceder que Aristóteles justifica mediante un principio obtenido por una sumaria inducción:

[Principio 1] Para todos aquellos que producen obras (ergon ti) o que desempeñan una actividad (praxis), en la obra que realizan se cree que residen el bien y la perfección $\left(\right.$ to eu). ${ }^{13}$

Esto significa que para determinar, por ejemplo, si alguien es un buen escultor, lo que hay que hacer es observar la calidad de sus obras. Nuestra valoración del individuo está subordinada a nuestra valoración de los productos de la actividad de ese individuo.

Nótese que este principio no dice que todo individuo deba realizar su obra específica, ni dice tampoco que la obra o ergon sea el bien o fin de los individios. En efecto, la mera producción de obras no es el bien del individuo, pues si, por ejemplo, las estatuas son de mala calidad, el individuo será un mal escultor y no es bueno para un escultor ser un mal escultor.

La interpretación correcta del principio será, por ende, la siguiente:

(Principio la) "Para todo $x$, si $x$ tiene una actividad característica $y$, entonces $x$ será un buen $x$, si y sólo si $x$ produce buenas instancias de $y . "$

Dado que para Aristóteles lo bueno para el ser humano es ser un buen ser humano, un individuo humano de buena calidad, se sigue que en la búsqueda del bien humano debemos identificar primero la actividad característica de los seres humanos. De lo contrario no podremos emitir el juicio valorativo previo sobre el cual descansa el juicio sobre el bien humano propiamente tal. Esto no significa que la mera identificación del ergon humano complete la tarea. Sólo significa que sabremos hacia dónde dirigir la mirada al tratar de establecer condiciones necesarias y suficientes para decidir cuándo una vida humana es una buena vida.

¿Cuál es, según Aristóteles, la obra característica del hombre? Como veremos, hay al menos cuatro expresiones dentro del contexto que estamos examinando que se refieren al ergon humano. La primera de ellas es la siguiente:

12 E.N. I, 7, 1097a 25-1097b, 21.

13 E.N. 1097b, 26-27, trad. Antonio Gómez Robledo (Aristóteles, Ética Nicomaquea, 2a ed., México, 1983). Nótese que en esta versión el término ergon es traducido a veces por "obra" y a veces por "acto". 


\section{praktike tis [sc. zoe] tou logon ejontos \\ "una vida activa de aquello que tiene logos $" 14$}

Esta expresión, como lo muestra un pasaje de la Politica (1325b 14 ss.), probablemente no está pensada como uno de los polos dentro de la oposición vida activa/vida contemplativa, sino que debe ser entendida en el sentido más general de la expresión praktike, aquel en virtud del cual también la contemplación es una actividad o praxis. Según esto, la obra definitoria del ser humano es la vida de aquello dentro de nosotros que posee razón o lenguaje. Típicamente humana, entonces, es la activación de la capacidad para pensar. Pensamiento y razón, por otra parte, se extienden a una gran variedad de actividades humanas y la suposición de que se trata de una "vida" parece confirmar la idea de que debermos entender la activación de la racionalidad en su máxima generalidad.

Si ahora recordamos la interpretación que dimos del principio general para la valoración de todo aquello que posee un ergon, lo que cabe esperar es que Aristóteles, habiendo ya identificado el ergon humano, pase ahora a juzgar cuándo las instancias de la activación del ergon son buenas y cuándo no.

Quisiera sugerir que ésta es precisamente la tarea de la extensa oración condicional de E.N. I 7, cuyo consecuente resulta ser la definición aristotélica de la felicidad.

III

Observemos entonces el pasaje en que Aristóteles fundamenta la adopción del punto de partida de su ética. En la versión de Antonio Gómez Robledo dice así:

$\mathrm{Si}$, pues, el acto (ergon) del hombre es la actividad del alma (psyjes energeias) según la razón, o al menos no sin ella (kata logon e me anou logou); y si decimos de ordinario que un acto (ergon) cualquiera es genéricamente el mismo, sea que lo ejecute un cualquiera o uno competente, como es el mismo, por ejemplo, el acto del citarista y el del buen citarista, y en general en todos los demás casos, añadiéndose en cada uno la superioridad de la perfección (kat'areten) al acto (ergon) mismo (diciéndose así que es propio del citarista tañer la cítara, y del buen citarista tañerla bien); si todo ello es así, y puesto que declaramos que el acto (crgon) propio del hombre es una cierta vida y que ella consiste en la actividad (energeia) y obras (praxeis) del alma en consorcio con el principio racional (meta logou), y que el acto de un hombre de bien es hacer todo ello bien y bellamente; y como, de otra parte, cada obra se ejecuta bien cuando se ejecuta según la perfección que le es

14 E.N. I, 7, 1098a, 3-4. Cf. J. A. Stewart, Notes on the Nicomachean Ethics of Aristotle, Oxford, 1892 (reimp. Nueva York, 1973), vol. I, p. 99). 
propia (kata ten oikeian areten), de todo esto se sigue que el bien humano resulta ser una actividad del alma según su perfección (kat'areten); y si hay varias perfecciones, según la mejor y más perfecta (kata ten aristen kai teleiotaten). ${ }^{15}$

En una primera lectura no resulta en absoluto claro cómo deba entenderse este célebre argumento. A modo de análisis propondría distinguir dentro de él tres conjuntos de ingredientes:

(A) Conviene observar, en primer lugar, que existe una base inductiva, es decir, algunas aserciones no controvertibles representadas por el ejemplo del citarista. Estas aserciones son:

(Al) "Un citarista y un buen citarista se dice que tienen el mismo ergon o actividad característica”.

(A2) "Lo propio del citarista es tañer la cítara y del buen citarista tañerla bien".

(B) El segundo conjunto de ingredientes consiste en dos generalizaciones obtenidas a partir de los ejemplos aducidos:

(BI) "Para todo agente $x$ que ejecuta un ergon o actividad característica y todo agente $y$ que ejecuta ese ergon bien, los erga o actividades características son genéricamente idénticos".

Esta generalización implica que la noción de ergon es una noción descriptiva y, por lo tanto, neutral. Por sí misma la mención de la actividad característica de algo no incluye ningún tipo de valoración. La buena y la mala ejecución no son, por cierto, estrictamente idénticas, de lo contrario no las juzgaríamos en forma diferente, pero son-como dice el texto- "genéricamente idénticas" en cuanto ambas son ejecuciones de un mismo tipo de actividad. La segunda generalización acentúa este punto:

(B2) "Para distinguir entre cualquier ejecutor y un buen ejecutor de una actividad característica, se debe agregar a la especificación de ésta la eminencia respecto a la excelencia".

En otras palabras, el reconocimiento de que alguien se desempeña bien como ejecutor de un tipo de obra o tarea implica dos juicios, lógicamente independientes el uno del otro. Primero está la descripción neutral del tipo de ergon en cuestión y luego viene el juicio en el cual se afirma que esa obra o actividad ha sido ejecutada en forma buena o excelente, algo que en griego se expresa diciendo que ha sido realizada kat'areten, "conforme a la virtud".

Quizás una manera apropiada de ilustrar esto sería imaginando que alguien viaja a un país lejano, digamos a la India, donde descubre que ciertos indivi-

${ }^{15}$ E.N. I, 7, 1098a, 7-18. 
duos tocan un instrumento semejante a la cítara. Los ve tocar y de esta manera reconoce genéricamente su ergon. Pero cuando se trata de juzgar cuáles de esos músicos son buenos ejecutantes, ya no basta constatar quién toca ese instrumento y quién no. Hace falta un conocimiento de las convenciones que determinan la calidad de ejecución dentro de esa cultura, se requiere saber los criterios con que ellos juzgan la excelencia.

Si esto es correcto, Aristóteles estaría diciendo que, en general, para identificar un buen ejemplar de una clase (es decir, lo que él llama el bien para esa clase) hay que dar dos pasos perfectamente distintos. Primero hay que identificar en forma no valorativa lo típico o peculiar de esa clase y luego hay que especificar en qué consiste una activación de buena calidad. Esto último equivale a descubrir la arete o las aretai, virtudes o excelencias, que corresponden específicamente a dicha clase. En consecuencia el ergon y el bien no se identifican, no son lo mismo.

(C) El tercer paso de la argumentación consiste en aplicar las generalizaciones al caso particular de los seres humanos.

Prácticamente ninguno de los comentaristas que he consultado lee el texto con una mínima conciencia de que Aristóteles, si es consecuente, debe ofrecer primero una especificación neutral del ergon humano. Esto ha llevado a interpretaciones muy confusas de las expresiones en que aparece el término logos (kata logon $\mathrm{c}$ me aneu logou, meta logou), pero esto es comprensible porque tanto en griego como en castellano y otras lenguas modernas es muy difícil emplear términos tales como "razón", "racional", "racionalmente" sin expresar una valoración positiva. Suena extraño decir que alguien actuó “en consorcio con el principio racional”, como traduce Don Antonio Gómez Robledo, para agregar en seguida que al hacerlo actuó en forma necia o reprochable.

¿No será, empero, falso que Aristóteles especifica el ergon humano sin introducir valoración alguna?

Para resolver esto no tenemos más remedio que observar las tres expresiones que Aristóteles utiliza dentro del argumento para designarlo:

(i) psyjes energeia kata logon e me aneu logou actividad del alma según logos o no sin logos

(ii) pyyjes energeia kai praxeis meta logou actividad del alma y acciones con logos

(iii) psyjes energeia

actividad del alma.

Me parece relativamente claro que lo que aparece en tercer lugar es una expresión incompleta cuya función es remitir a las dos expresiones anteriores. Éstas, cabe esperar, tienen que ser equivalentes, pero ¿exactamente en qué sentido? 
A mi juicio, y contra la opinión de la mayoría de los comentaristas, parece que no hay que entender la expresión meta logou en el mismo sentido que tiene una expresión semejante (meta tcu orthou logou) en VI, 13, 1144b, 2627 donde ésta sirve para expresar la interiorización de la recta razón. ${ }^{16} \mathrm{La}$ virtud, se lee allí, consiste en actuar no sólo conforme a la recta razón sino con recta razón. Allí la presencia de la palabra orthos indica que se trata de una valoración positiva.

En el pasaje que estamos examinando el término valorativo no aparece. Además, si lo damos por supuesto, tendremos como resultado la doctrina de que el ergon humano consiste en actuar conforme y con (recta) razón, es decir virtuosamente, lo cual haría pleonástica la insistencia de Aristóteles en que a la especificación del ergon "hay que añadirle la superioridad que consiste en la virtud". Por otra parte, es falso que lo típicamente humano sea actuar conforme a la virtud. A cada paso nos topamos con las fallas morales e intelectuales propias y ajenas y sería una osadía pretender que a tan fino observador del quehacer humano como Aristóteles se le haya escapado algo tan obvio.

¿Qué es entonces lo típicamente humano? Acciones con logos, es decir activaciones de ciertas capacidades que Aristóteles discute en su Metafisica y que allí contrasta con las alogoi dynameis, las potencias o capacidades irracionales. Él las llama explícitamente dynameis meta logou. ${ }^{17}$

La diferencia entre ambas clases de capacidades consiste en lo siguiente: Una capacidad sin logos produce sólo un tipo de efecto, por ejemplo, el calor sólo es capaz de calentar, nunca de enfriar. Una capacidad con logos, por el contrario, es capaz de producir efectos inversos, como el médico que es capaz de curar y de matar en virtud de su conocimiento técnico. Esto se debe a que "el logos manifiesta la cosa misma y su privación", 18 "pues es por negación y remoción que manifiesta lo contrario". ${ }^{19}$

El mostrar en detalle cómo Aristóteles entiende esto requeriría de un extenso análisis textual que no puedo ofrecer aquí. Lo importante para nuestros fines es que el hecho de ser una capacidad meta logou no garantiza que una determinada destreza o tejne vaya a ser empleada en forma buena. En efecto, al final del capítulo en que discute las potencias racionales, Aristóteles propone la siguiente generalización:

Es evidente que la potencia (dynamis) sólo de producir (poiein) o de padecer (pathein) está implícita en la potencia de producir bien, pero no siempre ocurre lo

16 Véase a modo de ejemplo representativo A. Grant, The Ethics of Aristotle ilustrado con ensayos y notas, Londres, 1885 (reimp. en Nueva York, 1973), vol. I, p. 450.

17 Met. IX, 2, 1046a, 36, 1046b, 1.

18 Met. IX, 2, 1046b, 8-9.

19 Met. IX, 2, 1046b, 13-14. 
contrario. Pues lo que produce un buen resultado, necesariamente produce, pero lo que sólo produce no produce necesariamente bien. ${ }^{20}$

Este texto es interesante por dos razones. La primera es que muestra que Aristóteles está perfectamente consciente de que es falaz inferir valores a partir de los hechos y posee por lo tanto el instrumental conceptual para resistir a la tentación de proveer una fundamentación fáctica para la ética. En segundo lugar, nos da la pista correcta para entender lo que quiere decir cuando afirma que el ergon humano consiste en actividad y acciones con logos.

Típicamente humanas son simplemente las acciones, rectas o incorrectas, buenas o malas, que van acompañadas de algún tipo de contenido proposicional que puede ser afirmado o negado por el agente. Caer enfermo o rodar involuntariamente por una escalera no son acciones humanas, poner una bomba o donarle un riñón a un hermano sí lo son. De estas últimas podemos dar razón, podemos afirmar o negar un contenido proposicional.

Con esto queda asegurada la interpretación de la segunda fórmula aristotélica para la obra del hombre. ¿Cómo entender la primera, la que decía que lo típicamente humano es actuar kata logon e me aneu logou, conforme a logos o no sin logos?

Sería ciertamente un error el pretender, con muchos comentaristas, que estas dos expresiones designan dos capacidades del alma: la capacidad racional y la capacidad apetitiva. ${ }^{21}$ En efecto, en ambos dominios es posible actuar kata logon, conforme a logos.

Hacerlo en el dominio de la capacidad apetitiva es ejercer la virtud moral. Si pongo mis deseos y pasiones en conformidad con un logos que me dice que no debo beber más de tantas copas o comer más de tantos platos, estaré ejerciendo la moderación o sofrosyne. ${ }^{22}$

Hacerlo en el dominio de la capacidad racional (to logon ejon) es ejercer una virtud intelectual. No hay, por ejemplo, tejne, arte, ni fronesis, prudencia, si no se actúa teniendo un contenido proposicional verdadero que indique, en un caso, que tal remedio es bueno para el paciente o, en el otro, que tal tipo de opción es buena para el agente. ${ }^{23}$ Kata logon, por lo tanto, indica valoración positiva. Me parece que ningún aristotélico ortodoxo negará esto. 1986).

${ }^{20}$ Met. IX, 2, 1046b, 24-28 (trad. Hernán Zucchi, Aristóteles, Metafisica, Buenos Aires,

21 Gauthier-Joliv, LÉthique d̀ Nicomaque, Lovaina/Paris, 1970, t. II, primera parte, p. 59; le atribuyen esta posición a numerosos estudiosos comenzando por el comentarista Eustratio. La más reciente aparición de esta interpretación es quizás la que subyace a la traducción de $T$. Irwin del pasaje en cuestión (Aristotle, Nicomachean Ethics, Indianápolis, 1985, p. 17).

22 Cfr. E.N. III, 12, 1119b, 10-16.

23 Para constatar la necesidad de logos verdadero en el arte y la prudencia, véase E.N. VI, 4, 1140a, 20-21 y VI, 5, 1140b, 20-21, respectivamente. 
Lo que me parece mucho más difícil es persuadir al más revisionista de los peripatéticos de que me aneu logou implica valoración negativa. ¿Por qué no empleó Aristóteles la expresión para logon o para ton logon para manifestar lo opuesto a una acción kata logon? Mi conjetura es que estas expresiones habrían generado aún más confusión que la que efectivamente usó.

Es verdad.que Aristóteles emplea ocasionalmente para ton logon en el sentido de "contrario a la razón", ${ }^{24}$ pero también la emplea para referirse a lo que constituye un dominio distinto del dominio de la razón. En E.N. I, 13 esta expresión introduce el factor apetitivo o desiderativo del alma, un factor que es diferente del que posee logos en sentido estricto ${ }^{25}$ y sus activaciones son ambivalentes: las hay buenas o moralmente virtuosas y las hay malas o viciosas. Además, las acciones que se ejecutan para logon en el sentido de que el agente está loco no cuentan como acciones típicamente humanas.

Me parece que una manera de ilustrar lo que llevó a Aristóteles a usar las palabras "no sin logos" es recurrir a un ejemplo paradigmático de valoración negativa de una acción.

Desde el periodo arcaico hasta los siglos V y IV la guerra fue una realidad casi cotidiana en Grecia. Ni siquiera los notables 50 años de florecimiento cultural entre las guerras contra Persia y la guerra del Peloponeso estuvieron desprovistos de conflictos. Más tarde la hegemonía tebana unida al crecimiento de Macedonia dieron lugar a pocas pausas en la actividad militar. Por ello, la valentía fue siempre una de las cualidades humanas más apreciadas entre los griegos y la cobardía una de las más denigradas. En efecto, el acto de cobardía más usual, el abandonar la línea de combate en la falange de hoplitas o tropas de infantería pesada resultaba ser muy peligroso para los compañeros de armas. Es el hueco dejado por el cobarde lo que destruye la ventaja táctica de la formación cerrada y le permite al enemigo atacar con probabilidades de éxito. Es natural entonces que la palabra deilos (de deos, "temor") que significa "cobarde" y, por ende, "vil", "miserable", "desdichado" sea uno de los peores insultos en griego.

Quien ha visto los pesados escudos preservados en los museos de Delfos o de Olimpia comprende bien que si el cobarde quiere salvarse, lo que tiene que hacer es desembarazarse de ese peso y correr lo más rápidamente posible. De allí que la pérdida del escudo sea por sí misma sinónimo de cobardía. Se dice que las madres espartanas le decían a sus hijos que esperaban que volviesen con el escudo o sobre él, vale decir, muertos pero no despojados de sus armas.

Ahora bien, entre los poetas líricos griegos encontramos algunos de esos magníficos personajes irreverentes que le dan su particular frescura a la Grecia 
arcaica. Tres de ellos, Arquíloco, Alceo y Anacreonte, no tienen el menor empacho en confesar que perdieron sus armas para salvar el pellejo. ${ }^{26}$ Según los cánones de la ética aristotélica no actuaron conforme al logos, 27 pero tampoco sus actos estuvieron totalmente desprovistos de logos. Les es posible decir por qué lo hicieron, les es posible racionalizar o al menos explicar su preferencia por la vida por sobre un valor anticuado, como la valentía homérica. Teniendo en cuenta su autopreservación, se puede decir que sus decisiones no fueron totalmente irracionales.

Tampoco las fallas en el dominio de las virtudes intelectuales son totalmente irracionales. No están desprovistas de logos. Un error prudencial o científico no es otra cosa que actuar o inferir a partir de un logos falso, pero logos al fin y al cabo.

Con esto creo haber mostrado que tanto en el dominio de la dimensión apetitiva como en el dominio de la dimensión intelectual propiamente tal, el no ajustarse a la razón no implica que no haya razón.

\section{IV}

Hasta este punto he tratado de mostrar que en la inferencia de la definición de bien humano las expresiones aristotélicas kata logon y me aneu logou corresponden a la valoración positiva y negativa de la acción y que la expresión meta logou incluye ambas posibilidades.

La premisa en que se hace referencia a la actividad característica del hombre, por lo tanto, no es valorativa sino puramente descriptiva. Esto no implica, sin embargo, que se infiera un valor a partir de un hecho.' Como vimos, Aristóteles está perfectamente consciente de que una inferencia tal sería falaz. ¿Cómo deduce entonces la definición de la felicidad?

La deducción requiere, en primer lugar, de una premisa valorativa y ésta corresponde a lo que inicialmente llamamos Principio la:

(1) "Para todo $x$, si $x$ tiene un ergon $y$, entonces $x$ será un buen $x$ si y sólo si produce buenas instancias de $y^{\prime \prime}$.

Luego sigue la reducción al caso particular del ser humano designando la actividad característica de éste:

(2) "El ergon del ser humano es actividad con logos".

De allí la conclusión:

(3) "Un ser humano será un buen ser humano si y sólo si produce buenas instancias de actividad con logos".

26 Cfr. D. A. Campbell, The Golden Lyre, The themes of the Greek lyric poets, Londres, 1983, Pp. 85 y 100.

27 E.N. III, 7, 1115b, 19-20. 
En otras palabras, el bien humano se alcanza cuando se actúa conforme a las excelencias o virtudes propiamente humanas pues en esto consiste el producir buenas instancias de dichos actos.

Con esto se ha formulado el principio primero, es decir, la meta última de la ética. La tarea práctica de alacanzarla requiere saber en qué consiste cada una de las excelencias o virtudes pues ellas proveen los criterios para juzgar nuestros actos. La Ética Nicomaquea luego de dividir las virtudes en morales e intelectuales procede, entre los libros II y IX, a analizarlas una por una.

¿En qué consistió entonces el proceso de fundamentación de la ética aristotélica? Consistió simplemente en justificar el valor último para los seres humanos a partir de un principio muy general de valoración, un principio que probablemente utilizamos todos consciente o inconscientemente cuando tenemos que escoger algo: nos preguntamos si el objeto en cuestión desempeña bien la función o tarea que se espera de él. Creo que sería inexacto hablar en este caso de un principio metafísico. Hasta donde alcanzo a divisar, no hay nada en la Metafisica de Aristóteles que se le asemeje. Lo más importante, empero, es que no se requiere saber metafísica para aceptarlo (y para aceptar, en consecuencia, el punto de partida de la ética).

Se podrá objetar que en el proceso de determinar la obra específica del ser humano se alude en I, 7 a los tres niveles de vida (vegetativo, sensitivo y racional) distinguidos cuidadosamente en el De Anima. ${ }^{28}$ iNo es esto fundar la ética sobre una psicología racional? Me parece que no. En realidad el texto de I, 7 no hace ninguna referencia a nous o noien, al intelecto o al inteligir, a su operación en relación con la fantasía, etc., vale decir, a ninguna de las doctrinas distintivamente aristotélicas en psicología. En efecto, la caracterización del ergon humano en sus cuatro formulaciones es tan general y vaga que sería impropio decir que es el resultado de una indagación psicológica. No se requiere estudio alguno del De Anima para aceptar la tesis de que los seres humanos y sólo los seres humanos pueden dar una justificación lingüística de sus actos, ya sea que ese logos o afirmación sea verdadero o falso, convincente o no convincente, una justificación aceptable o una mera racionalización.

Para terminar quisiera regresar al problema de la función de la naturaleza humana en la fundamentación de la ética aristotélica. Aparte del uso de pefyke en una pregunta retórica, ${ }^{29}$ el argumento analizado no apela en ningún momento a la noción de naturaleza para apoyar la conclusión. La conclusión es, como vimos, valorativa pero no provee por sí misma criterios normativos. Estos criterios, se dijo, fluyen del concepto de cada una de las virtudes o excelencias. 
En otras palabras, de acuerdo con la ética aristotélica algo debe hacerse no porque sea natural o esté en conformidad con la naturaleza humana, sino porque es virtuoso, es decir, bueno, hacerlo. Que la valentía esté ligada a la noción normativa de naturaleza humana y que no lo esté la cobardía se explica ahora como una noción fundada y no fundante. Es porque es bueno ser valiente y malo ser cobarde que concebimos a la valentía como un atributo que un ser humano debería poseer. Primero tenemos que decidir qué constituye un atributo valorativamente positivo y luego podremos considerarlo como parte de la noción de naturaleza humana.

Creo que esto abre otras preguntas que no podemos comenzar a discutir aquí, pero creo haber contribuido al menos a disipar una concepción errónea de la fundamentación de la ética aristotélica. 